\title{
Contrast effects in instrumental differential conditioning with a non-nutritive liquid reinforcement
}

BETTY B. ROSSMAN AND M. J. HOMZIE 2 UNIVERSITY OF DENVER

Rats were assigned either to one of three treatment groups which experienced identical xylose $S$-incentives and $S+r e-$ wards that differed in volume and/or concentration from the $S$ - reward, or to a control group which always received the $S$ incentive. These groups received differential conditioning for 134 acquisition and 68 reversal trials. Negative simultaneous contrast effects (CEs) were observed during acquisition and reversal training. These CEs were greater the larger the difference in volume and/or concentration between the $S+$ and $S$ incentive values.

Since the initial work by Crespi (1944), many studies have demonstrated incentive contrast effects (CEs) using differential magnitudes or concentrations of nutritive rewards associated with the positive (S+) and negative or less favorable (S-) discriminanda. However, few have assessed the effects of nonnutritive reward or the simultaneous variation of reward quantity and quality (e.g., Berkley, 1963) on contrast behavior during acquisition. The literature is even more limited concerning the effects of these parameters during reversal learning.

Though the prior evidence is somewhat limited, it does suggest: (a) that the greater the contrast between the S+ and S- incentive values, the greater the CEs (Davenport, 1962) and (b) that the presence of a nutritive reward is not necessary in the production of contrast behavior (Berkley, 1963). It remains unclear whether both aspects of a liquid reward, quantity and quality, are potent in producing $\mathrm{CEs}$, and if their effects on performance combine to produce a greater $\mathrm{CE}$ than either parameter acting alone.

This study investigated the effects of a nonnutritive liquid reward on contrast behavior during acquisition and reversal learning. The design involved four groups which received identical nonnutritive, less favorable (S-) rewards.

\section{Method}

The apparatus consisted of two runways. One runway and goalbox were painted flat black; the other runway and goalbox were flat white. There was a guillotine door located 9 in. from the end of each alley (to prevent retracing from the goalbox section). A Standard electric clock timed S's latency over a 2-ft distance between the opening of the startbox door and S's depressing a floor plate just in front of the goalcup.

Fifty-two experimentally naive female albino rats of the Wistar strain were randomly assigned to the four experimental groups. In one treatment group
(CA-SV) both the consummatory activity and sweetness of the reward were varied between conditions: Ss received $.4 \mathrm{ml}$ of $16 \%$ xylose solution in one alley as Condition $\mathrm{CA}-\mathrm{SV}+$, the positive discriminandum, and $.1 \mathrm{ml}$ of $4 \%$ xylose solution in the other alley as Condition $\mathrm{CA}-\mathrm{SV}-$, the negative discriminandum. In the second treatment group (SV), consummatory activity was equated between conditions, but sweetness varied: Ss received .1 $\mathrm{ml}$ of $16 \%$ xylose solution in one alley as Condition $\mathrm{SV+}$, and $.1 \mathrm{ml}$ of $4 \%$ solution in the other as Condition SV-. In the third treatment group (CAV), sweetness was held constant between conditions, but consummatory activity varied. Ss received $.4 \mathrm{ml}$ of $4 \%$ solution in one alley as Condition CAV+, and .1 ml of $4 \%$ solution in the other as Condition CAV-. For the Control group the xylose solution associated with both the positive and negative discriminanda were .1 $\mathrm{ml}$ of $4 \%$ solution, thus removing any reward contrast between discriminanda and equating the reward the Control Ss always received with the S- incentive received by the three experimental groups.

On the first day of runway testing, Ss were given one trial in each alley, and on the following 33 acquisition days Ss received two forced trials to each discriminandum. Each $S$ received its daily trials in alternation with five or six other animals.

On the 35th day of testing the reward conditions were reversed. All other procedures remained the same; Ss were tested on the reversal task for an additional 17 days.

\section{Resulfs and Discussion}

The overall acquisition and reversal performance to the negative discriminandum as a function of stage of practice for the various groups is summarized in Fig. 1.3 In general, the groups performed in the following order: Control, $\mathrm{CAV}-, \mathrm{SV}-$, and CA-SV-.

The Mann-Whitney $U$ test was used to compare the performances of the groups to their identical less favorable reward conditions. When considering the data for all 134 acquisition trials, the comparisons between $\mathrm{CA}-\mathrm{SV}$ - and SV-, and $\mathrm{CA}-\mathrm{SV}$ - and the Control group, were both statistically significant $(p<.05$ onetailed and $\mathrm{p}<.05$, respectively). When only the data for Trials 63-134 (after discrimination had occurred for all groups) were analyzed, the comparisons mentioned above reached a higher level of significance and, in addition, the comparison between CA-SV- and CAVbecame statistically reliable $(p<.05, .02, .05$, re- 


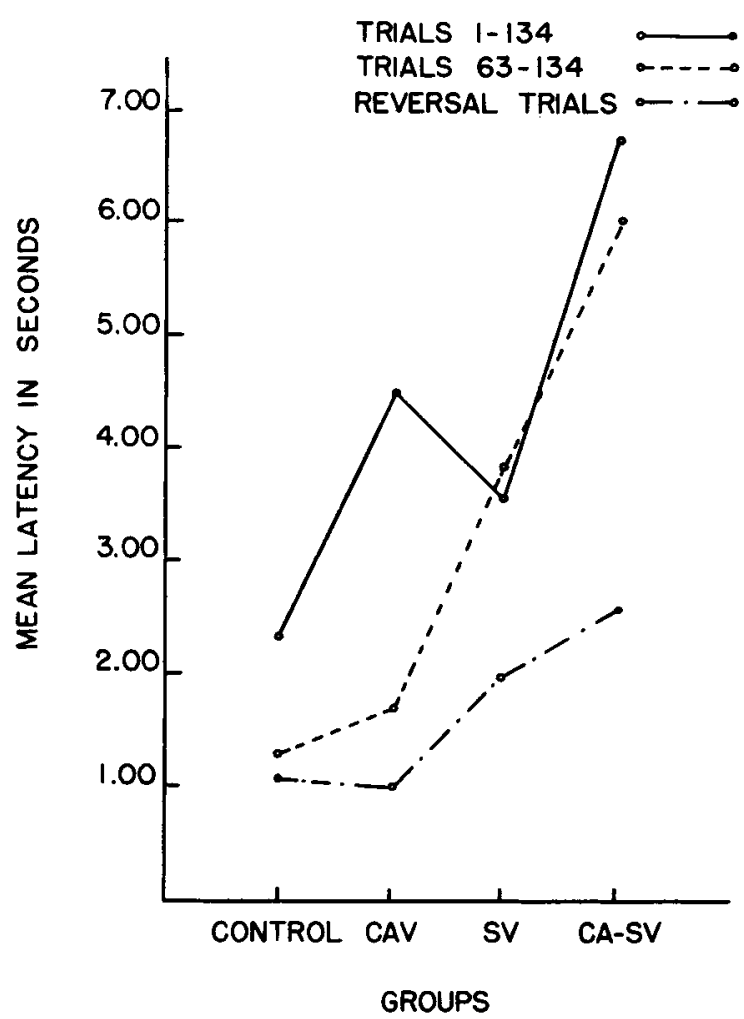

Fig. 1. Average latency in seconds to the negative discriminandum for each group as a function of stage of training.

spectively). Thus, for Trials 63-134, the extent of the differences between groups (see Fig. 1) in performance to the $\mathrm{S}-$ condition is greater than it is when all acquisition trials are considered. Turning to the reversal data, the Mann-Whitney $U$ tests indicated that the comparisons between CA-SV- and CAV-, and between SV- and CAV-, were both statistically significant $(p<.05$, .02 , respectively). Since the reward condition associated with the negative discriminandum was the same in each of the above comparisons (i.e., $.1 \mathrm{ml}$ of $4 \%$ xylose solution), these data indicate that response latency was a function of the reward associated with the positive discriminandum.

Also of interest is whether or not $\mathrm{S}+: S-$ contrast in incentive magnitude (volume) has a different effect on performance than S+:S- contrast in reward quality (concentration) and if these two parameters combine to produce a still greater CE. The S+:S- concentration contrast used in the present experiment (i.e., Group SV) was more effective in depressing performance to the negative reward than the $S+: S-m a g n i t u d e$ contrast (i.e., Group CAV), and the combined effects of these two parameters (i.e., Group CA-SV) produced the greatest decrement in performance to S-. Thus, the results indicate that negative $\mathrm{CEs}$ were produced by a nonnutritive reward during both acquisition and reversal learning, and that contrast in volume and concentration combined to produce a greater CE than did either parameter acting independently.

References

BERKLEY, M. A. Discrimination of rewards as a function of contrast in reward stimuli. J. exp. Psychol, 1963, 66, 371-376.

CRESPI, L. P. Amount of reinforcement and level of performance. Psychol Rev., 1944, 51, 341-357.

DAVENPORT, J. W. The interaction of magnitude and delay of reinforcement in spatial discrimination. J. comp. physioL Psychol, 1962, $55,267-273$.

Notes

1. This report is based on a M.A. thesis completed by the first author under the second author's direction. This research was partially supported by NSF Grant GY-2068.

2. Now at the University of Virginia.

3. The mean differences between SV-/Control (Trials 63-134) and CA-SV-

/Control (reversal) were inflated by one extreme score. 